\title{
Multi-cracks identification based on the nonlinear vibration response of beams subjected to moving harmonic load
}

\author{
H. Chouiyakh ${ }^{1}$, L. Azrar ${ }^{1,2,3}$, O. Akourri ${ }^{1}$, and K. Alnefaie ${ }^{3}$ \\ ${ }^{1}$ Mathematical Modeling and Control, FST of Tangier, Abdelmalek Essaâdi University; Tangier; Morocco \\ ${ }^{2}$ LaMIPI, Higher School of Technical Education of Rabat (ENSET), Mohammed V University in Rabat, Morocco \\ ${ }^{3}$ Mechanical Engineering Department, Faculty of Engineering, King Abdulaziz University, Jeddah, Saudi Arabia
}

\begin{abstract}
The aim of this work is to investigate the nonlinear forced vibration of beams containing an arbitrary number of cracks and to perform a multi-crack identification procedure based on the obtained signals. Cracks are assumed to be open and modelled trough rotational springs linking two adjacent sub-beams. Forced vibration analysis is performed by a developed time differential quadrature method. The obtained nonlinear vibration responses are analyzed by Huang Hilbert Transform. The instantaneous frequency is used as damage index tool for cracks detection.
\end{abstract}

\section{Introduction}

Vibration based techniques of damage identification aim to combine mathematical models with signal processing techniques. Relevant work has been published in this regard [1], but they almost assume that structures and damages behave linearly while in reality signals are nonlinear. Thus, the structural health monitoring researchers appeal to mathematical models of nonlinear dynamics [2, 3]. The problem of vibration of multicracked beams subjected to moving loads has also attracted many researchers [4] where free and forced vibrations of the beam are investigated. However, the linear case is usually considered and the forced response is computed following classical schemes of integration mainly the Runge-Kutta method [5,6]. On the other hand, cracks identification is concerned by analysing the vibration signals using adapted techniques. The focus will be here on time frequency methods known for their local properties in both time and frequency domains [7].

In parallel with our previous work $[8,9]$, this paper focuses on the nonlinear behaviour of multi-cracked beams subjected to moving harmonic load. For the free and forced responses, a numerical method based on the differential quadrature method has been developed. Crack identification procedures are elaborated based on the numerically computed nonlinear responses.

\section{Mathematical formulation}

Consider a multi-cracked Euler-Bernoulli beam with length $\mathrm{L}$, cross-section A, mass density $\rho$, moment of inertia I, and modulus of elasticity $\mathrm{E}$ that is subjected to a moving harmonic load of magnitude $\mathrm{F}_{0}$, speed $\mathrm{v}$ and excitation frequency $\Omega$, and $\mathrm{R}$ is the number of existing cracks as shown in figure 1. It is assumed that the crosssectional area of the beam is rectangular and its material is homogenous. The ' $R$ ' cracks are assumed to be open and modelled through rotational springs which flexibilities are given by fracture mechanics [8]. The whole beam is sub-divided into $(\mathrm{R}+1)$ sub-beams.

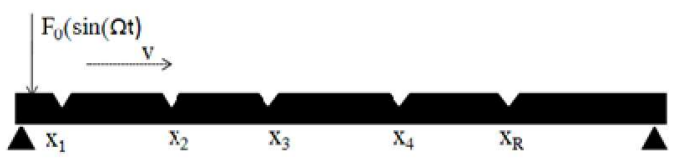

Fig. 1. Multi-cracked beam under a moving harmonic load

The equation of motion for the $i^{\text {th }}$ mode of vibration is given by:

$\mathrm{m}_{\mathrm{ii}} \ddot{\mathrm{q}}_{\mathrm{i}}^{(\mathrm{r})}+\mathrm{c}_{\mathrm{ii}} \dot{\mathrm{q}}_{\mathrm{i}}^{(\mathrm{r})}+\mathrm{k}_{\mathrm{ii}} \mathrm{q}_{\mathrm{i}}^{(\mathrm{r})}+\beta_{\mathrm{ii}} \mathrm{q}_{\mathrm{i}}^{3^{(\mathrm{r})}}=\mathrm{F}_{\mathrm{i}}^{(\mathrm{r})}(\mathrm{t}) \quad \frac{\mathrm{x}_{\mathrm{r}-1}}{\mathrm{v}} \leq \mathrm{t} \leq \frac{\mathrm{x}_{\mathrm{r}}}{\mathrm{v}}(1)$

where: $\mathrm{m}_{\mathrm{ii}}, \mathrm{c}_{\mathrm{ii}}, \mathrm{k}_{\mathrm{ii}}, \beta_{\mathrm{ii}}$ are modal parameters defined as follows:

$$
\begin{aligned}
& \mathrm{m}_{\mathrm{ii}}=\rho \mathrm{A} \sum_{\mathrm{r}=1}^{\mathrm{R}+1} \int_{\mathrm{x}_{\mathrm{r}-1}}^{\mathrm{x}_{\mathrm{r}}} \mathrm{w}_{\mathrm{i}}(\mathrm{x}) \mathrm{w}_{\mathrm{i}}(\mathrm{x}) \mathrm{dx} \\
& \mathrm{c}_{\mathrm{ii}}=\eta \sum_{\mathrm{r}=1}^{\mathrm{R}+1} \int_{\mathrm{x}_{\mathrm{r}-1}}^{\mathrm{x}_{\mathrm{r}}} \mathrm{w}_{\mathrm{i}}(\mathrm{x}) \mathrm{w}_{\mathrm{i}}(\mathrm{x}) \mathrm{dx} \\
& \mathrm{k}_{\mathrm{ii}}=\mathrm{EI} \sum_{\mathrm{r}=1}^{\mathrm{R}+1} \int_{\mathrm{x}_{\mathrm{r}-1}}^{\mathrm{x}_{\mathrm{r}}} \mathrm{w}_{\mathrm{i}}^{\prime \prime \prime}(\mathrm{x}) \mathrm{w}_{\mathrm{i}}(\mathrm{x}) \mathrm{dx}
\end{aligned}
$$




$$
\begin{aligned}
& \beta_{\mathrm{ii}}=-\frac{\mathrm{EA}}{2 \mathrm{~L}} \sum_{\mathrm{r}=1}^{\mathrm{R}+1} \int_{\mathrm{x}_{\mathrm{r}-1}}^{\mathrm{x}_{\mathrm{r}}} \mathrm{w}_{\mathrm{i}}^{\prime \prime}(\mathrm{x})\left(\int_{\mathrm{x}_{\mathrm{r}-1}}^{\mathrm{x}_{\mathrm{r}}}\left(\mathrm{w}_{\mathrm{i}}^{\prime}(\mathrm{x})\right)^{2} \mathrm{dx}\right) \mathrm{w}(\mathrm{x}) \mathrm{dx} \\
& \mathrm{F}_{\mathrm{i}}^{(\mathrm{r})}(\mathrm{t})=\rho \mathrm{A} \sum_{\mathrm{r}=1}^{\mathrm{R}+1} \int_{\mathrm{x}_{\mathrm{r}-1}}^{\mathrm{x}_{\mathrm{r}}} \mathrm{F}_{0} \sin (\Omega \mathrm{t}) \delta(\mathrm{x}-\mathrm{vt}) \mathrm{w}_{\mathrm{i}}(\mathrm{x}) \mathrm{dx}
\end{aligned}
$$

$\mathrm{x}_{0}$ and $\mathrm{x}_{\mathrm{R}+1}$ correspond respectively to the left and right boundaries of the beam $(\mathrm{x}=0$ and $\mathrm{x}=\mathrm{L})$.

Note that the eignemode of a multi-cracked beam is written as [8]:

$$
\mathrm{w}_{\mathrm{i}}(\mathrm{x})=\mathrm{w}_{1}(0)+\sum_{\mathrm{r}=1}^{\mathrm{n}} \mathrm{w}_{\mathrm{ri}}(\mathrm{x})\left(\mathrm{H}\left(\mathrm{x}-\mathrm{x}_{\mathrm{r}-1}\right)-\mathrm{H}\left(\mathrm{x}-\mathrm{x}_{\mathrm{r}}\right)\right)+\mathrm{w}_{\mathrm{R}+1}(\mathrm{~L})
$$

The present problem is a set of coupled differential equations which has been solved for the linear case $(\beta=0)$ method [8].

Due to the fact that the excitation term depends on piecewise mode, the classical numerical methods cannot be used. In this work, a new numerical approach based differential quadrature method (DQM) has been developed in time domain for nonlinear analyses.

\subsection{Differential quadrature method}

The Differential quadrature method (DQM) was first introduced by Bellman and developed by many researchers [10]. The DQM requires the discretization of the problem into $\mathrm{N}$ points. The derivatives at any point are approximated by a weighted linear summation of all the functional values along the discretized domain, as follows [10]:

$$
\left\{\begin{array}{l}
\ddot{\mathrm{q}}\left(\mathrm{t}_{\mathrm{i}}\right)=\sum_{\mathrm{i}=1}^{\mathrm{N}} \mathrm{b}_{\mathrm{ij}}^{(2)} \mathrm{q}\left(\mathrm{t}_{\mathrm{j}}\right) \\
\dot{\mathrm{q}}\left(\mathrm{t}_{\mathrm{i}}\right)=\sum_{\mathrm{i}=1}^{\mathrm{N}} \mathrm{b}_{\mathrm{ij}}^{(1)} \mathrm{q}\left(\mathrm{t}_{\mathrm{j}}\right)
\end{array}\right.
$$

$\mathrm{N}$ is the number of distretizing points, $\mathrm{b}_{\mathrm{ij}}^{(1)}$ and $\mathrm{b}_{\mathrm{ij}}^{(2)}$ are the first and second order weighting coefficients respectively. The weighting coefficients for the first order derivative to the functional values can be obtained as:

$$
\begin{gathered}
b_{k j}^{(1)}= \begin{cases}\frac{L(f)}{\left(t_{k}-t_{j}\right) L_{l}\left(t_{j}\right)} & k \neq j \\
-\sum_{j=1, j \neq k}^{N} b_{k j}^{(1)} & k=j\end{cases} \\
L\left(t_{k}\right)=\prod_{i=1}^{N}\left(t_{i}-t_{k}\right)
\end{gathered}
$$

The second, third and higher derivatives can be calculated as:

$$
\mathrm{b}_{\mathrm{kj}}^{(\mathrm{m})}=\sum_{\mathrm{j}=1, \mathrm{j} \neq \mathrm{k}}^{\mathrm{N}} \mathrm{b}_{\mathrm{kl}}^{(1)} \mathrm{b}_{\mathrm{lj}}^{(\mathrm{m}-1)}
$$

The $\mathrm{N}$ discretizing points are calculated through:

$$
\mathrm{t}_{\mathrm{j}}=\frac{1}{2}\left[1-\cos \left(\frac{\mathrm{j}-1}{\mathrm{~N}-1} \pi\right)\right] \quad \mathrm{j}=1,2, \ldots, \mathrm{N}
$$

In this work, a new approach for solving nonlinear differential equations by introducing a correction loop in for calculating nonlinear response is presented. Applying the DQ method in each sub-beam Eq.(1) can be discretized as:

$$
\left.\left([\mathrm{M}]+[\mathrm{C}]+[\mathrm{K}]+[\mathrm{B}]\left\{\mathrm{q}^{2}\right\}^{\mathrm{r}}\right)\{\mathrm{q}\}\right\}^{\mathrm{r}}=\{\mathrm{F}\}^{\mathrm{r}}
$$

where: $[\mathrm{M}]=\mathrm{m}_{\mathrm{ii}} \mathrm{b}_{\mathrm{kj}}^{(2)} ;[\mathrm{C}]=\mathrm{c}_{\mathrm{ii}} \mathrm{b}_{\mathrm{kj}}^{(1)} ;[\mathrm{K}]=\mathrm{k}_{\mathrm{ii}} \operatorname{Id}(\mathrm{N}, \mathrm{N})$; and $[\mathrm{B}]=\beta_{\mathrm{ii}} \operatorname{Id}(\mathrm{N}, \mathrm{N})$.

We first set $[B]=0$. The linear solution for the $r^{\text {th }}$ time interval is obtained by solving the algebraic problem.

$$
\{\mathrm{q}\}^{\mathrm{r}}=([\mathrm{M}]+[\mathrm{C}]+[\mathrm{K}])^{-1}\{\mathrm{~F}\}^{\mathrm{r}}
$$

In order to calculate non linear response, for the subbeam ' $r$ ', we propose an iterative process written as:

$$
\{\mathrm{q}\}_{\mathrm{i}+1}^{\mathrm{r}}=([\mathrm{M}]+[\mathrm{C}]+[\mathrm{K}])^{-1}\left(\{\mathrm{~F}\}^{\mathrm{r}}-[\mathrm{B}]\left\{\mathrm{q}^{2}\right\}_{\mathrm{i}}^{\mathrm{r}}\right)
$$

The residue $\mathrm{R}_{\mathrm{i}+1}$ is calculated by:

$$
R_{i+1}^{r}=\left|[M]^{r}\{q\}_{i+1}^{r}+[C]^{r}\{q\}_{i+1}^{r}+[K]^{r}\{q\}_{i+1}^{r r}+[B]^{r}\left\{q^{3}\right\}_{i+1}^{r}-\{F\}\right|
$$

The stopping criterion is taken as

$$
\frac{\mathrm{R}_{\mathrm{i}+1}^{\mathrm{r}}}{\mathrm{R}_{1}^{\mathrm{r}}} \leq \varepsilon
$$

\section{Huang Hilbert transform: an overview}

As the identification process, used in this paper, will be based on the Huang Hilbert transform, an overview on the empirical mode decomposition and Hilbert transform is given

\subsection{Empirical mode decomposition}

The Empirical mode decomposition (EMD) is a technique representing non linear and non-stationary signals as sum of simpler components called Intrinsic Mode Functions (IMFs). An IMF should satisfy the following conditions:

a) An IMF may only have one zero between successive extrema

b) An IMF must have zero local mean

The decomposition is performed through a repeated sifting procedure. At the end, the time signal $x(t)$ can be expressed in terms of $n$ number of IMFs:

$$
\mathrm{s}(\mathrm{t})=\sum_{\mathrm{i}=1}^{\mathrm{n}} \operatorname{IMF}_{\mathrm{i}}(\mathrm{t})+\text { residue }
$$

The Hilbert transform is then applied to each of those components, in order to get instantaneous amplitude and frequency plots.

\subsection{Hilbert transform}

The Hilbert Transform (HT) of a signal $s(t)$, is an integral transformation, from time domain to time domain, defined by [7] :

\subsection{Nonlinear forced response using the time differential quadrature method}




$$
H(s(t))=\frac{1}{\pi} \int_{-\infty}^{+\infty} \frac{s(\tau)}{t-\tau} d \tau
$$

The HT is the convolution of $s(t)$ with $1 / t$ and hence emphasizes the local properties of $s(t)$. The real signal $s(t)$ and its HT $h(t)$, form an analytical complex signal $\widetilde{S}(t)$ of the form :

$$
\widetilde{S}(t)=s(t)+i h(t)=A(t) e^{i \theta(t)}
$$

The instantaneous $A(t)$ and phase $\theta(t)$ change with time. The instantaneous amplitude $\mathrm{A}(\mathrm{t})$ or envelope, is given by:

$$
A(t)= \pm \sqrt{(s(t))^{2}+(h(t))^{2}}
$$

where the " \pm " signs correspond to the upper positive and the lower negative envelops

$$
\theta(\mathrm{t})=\operatorname{Arctan}\left(\frac{\mathrm{h}(\mathrm{t})}{\mathrm{s}(\mathrm{t})}\right)
$$

The instantaneous frequency (IF) is defined as the derivative of the phase:

$$
\omega(\mathrm{t})=\frac{\mathrm{d} \theta(\mathrm{t})}{\mathrm{dt}}
$$

It measures the rate and direction of a phase in the complex plane. It can be estimated by different algorithms [7].

\section{Numerical results and discussion}

\subsection{Nonlinear forced response}

In order to validate the previous developments, an EulerBernoulli beam with the following material properties is considered: Young's modulus E $=210 \mathrm{GPa}$, material mass density $\rho=7860 \mathrm{~kg} / \mathrm{m}^{3}$ and Poisson ratio $v=0.3$. The geometrical parameters of the beam are selected as: depth $\mathrm{h}=0.01 \mathrm{~mm}$, thickness $\mathrm{b}=0.01 \mathrm{~mm}$. First, comparison is made with the reference [11] for the non cracked linear case. The obtained results are plotted in figure 2 and are the same as those presented in [11]

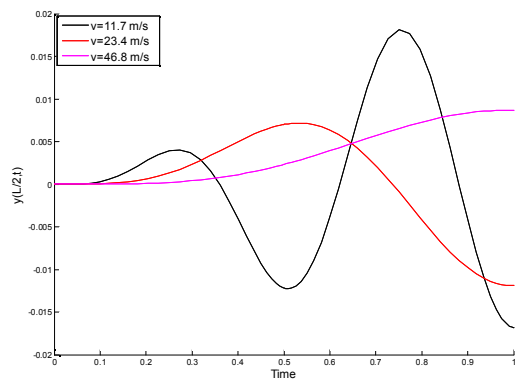

Fig. 2. Dynamic response of a pinned-pinned beam, varying the speed for $\Omega=\omega_{\text {resonance }}$

For the nonlinear case, the numerically obtained forced responses of a multi-cracked beam are depicted for various speeds and different frequencies in figure 3 . It is assumed that the beam contains four equally spaced cracks of equal depth $(\mathrm{a} / \mathrm{h}=0.1)$ located at $\mathrm{x} / \mathrm{L}=0.1 ; 0.3$; 0.5 and 0.7 .
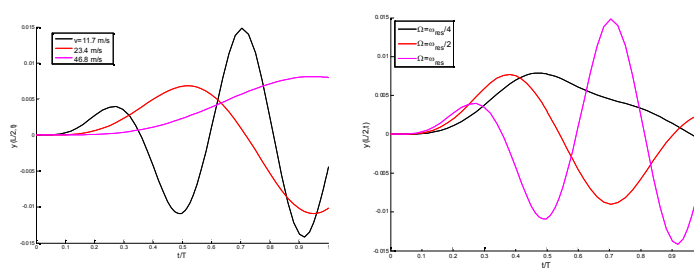

Fig. 3. Dynamic response of a pinned-pinned beam, varying the speed for different speeds $\left(\Omega=\omega_{\text {resonance }}\right)$ and different load frequencies $(\mathrm{v}=11.7 \mathrm{~m} / \mathrm{s})$

\subsection{Multi-cracks identification}

As the main aim of this work is to investigate crack detection from nonlinear signals, we propose to combine Huang Hilbert transform to moving load properties for a better cracks identification. For that, the nonlinear signal, depicted in figure 4, is decomposed into simpler components (IMFs) using the EMD, then Hilbert spectral analysis is applied to each of those IMFs.

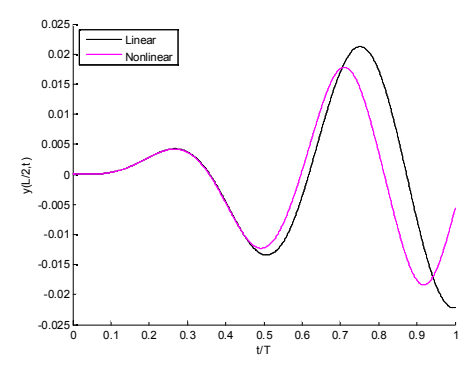

Fig. 4. Analyzed nonlinear signal

We notice that instantaneous frequency of the first IMF identifies positions of all cracks that are localized by sharp transitions in the curve. This is due to the presence of high frequency components in the signal at these locations as shown in figure 5 . It should be noted that large peaks are obtained leading to clear crack position detection.

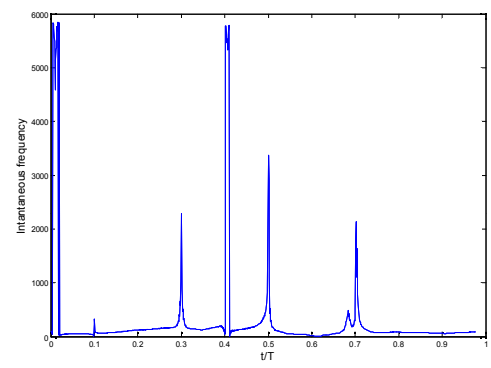

Fig. 5. Instantaneous frequency of the first IMF for $v=11.7$ and $\Omega=\omega_{\text {resonance }}$ 
Moreover, a better detection is obtained for selected values of the speed $v$ and excitation frequency $\Omega$. In this work we obtain them by trial and found that the best detection is obtained for $\Omega=\omega$ resonance and $\mathrm{v}=11.7 \mathrm{~m} / \mathrm{s}$ as shown in figure 5 . In spite of that, there are other peaks in the curve which means that there are other higher frequency components in the analyzed signals. This is due to the fact that the nonlinear signal contains various other harmonics and these harmonics may contain other information about cracks positions. For efficient multicracks identification based on the nonlinear responses some filters and a deep analysis is required.

\section{Conclusion}

We developed a numerical algorithm based on the time differential quadrature method in order to get the forced responses of multi-cracked beams under moving harmonic load.

A large number of cracks can be easily considered for the direct problem and identified for the inverse problem. We used for cracks identification Huang Hilbert transform. Higher frequency components are first detected and for the nonlinear case, not only cracks produce sharp transitions in the curve of instantaneous frequency but also some nonlinear signal components. We cannot accurately define those components since we lack of explicit analytic solutions for the multi-cracked beam vibration problems.

The identification is performed for selected values of the speed and excitation frequency. Adjusted values lead to better multi-cracks detection. An optimization procedure can be elaborated to predict the best $\mathrm{v}$ and $\Omega$ parameters.

\section{References}

1. C. Boller, C. Fou-Kuo, and F. Yozo. Encyclopedia of structural health monitoring. John Wiley \& Sons, (2009).

2. A.H.Nayfeh, F. Pai. Linear and Nonlinear Structural Mechanics. Wiley, May (2004)

3. Y.C Chu, H.H Shent. Analysis of Forced Bilinear Oscillators and the Application to cracked beam dynamics. AIAA journal, (1992): 2512-2519.

4. Bajer, Czesław I., and Bartłomiej Dyniewicz. Numerical analysis of vibrations of structures under moving inertial load. Vol. 65. Springer Science \& Business Media, 2012.

5. N.Roveri, and A. Carcaterra. Damage detection in structures under traveling loads by Hilbert-Huang transform. Mechanical Systems and Signal Processing 28 (2012): 128-144.

6. A. Ariaei, S. Ziaei-Rad, and M. Ghayour. Repair of a cracked Timoshenko beam subjected to a moving mass using piezoelectric patches. International Journal of Mechanical Sciences 52.8 (2010): 10741091.

7. M. Feldman, Hilbert transform in vibration analysis. Mechanical systems and signal processing 25, 3 (2011): 735-802.
8. H. Chouiyakh, L. Azrar, K. Alnefaie and O. Akourri. Multicracks identification of beams based on moving harmonic excitation. Structural Engineering and Mechanics, 58, 6 (2016)

9. H. Chouiyakh, L. Azrar, K. Alnefaie and O. Akourri. Vibration and multi-crack identification based on the free and forced responses of Timoshenko beams under moving mass using the differential quadrature method. Submitted to International Journal of Mechanical Sciences

10. Z. Zong and Z. Yingyan, Advanced differential quadrature methods. CRC press, 2009.

11. M. Abu-Hilal and M. Mohsen. Vibration of beams with general boundary conditions due to a moving harmonic load. Journal of Sound and Vibration 232, 4 (2000): 703-717. 